\title{
Impaired reflex responses to airway occlusion in the inspiratory muscles of asthmatic subjects
}

\author{
J E Butler, D K McKenzie, S C Gandevia
}

\begin{abstract}
Background-Asthmatic subjects have an impaired capacity to activate the diaphragm during attempted maximal inspiratory efforts. Limb muscles require reflex facilitation to achieve maximal force. The reflex responses of inspiratory muscles to airway occlusion in asthmatic subjects were measured and compared with those in non-asthmatic control subjects.

Methods - Nine healthy asthmatic subjects breathed at a constant inspiratory flow through a low resistance valve. Random inspirations were transiently occluded for $250 \mathrm{~ms}$. Surface electromyographic activity (EMG) was recorded over the scalene muscles, parasternal intercostal muscles, and the lateral chest wall overlying the diaphragm. The asthmatic subjects were studied with and without bronchoconstriction. Responses were compared with data from a matched group of 12 control subjects.
\end{abstract}

Results-Compared with the reflex responses to airway occlusion in control subjects, the duration of the initial short latency inhibition of inspiratory muscles was prolonged by $50 \%$ in asthmatic subjects and the size of the subsequent excitation was reduced by $30 \%$. Bronchoconstriction reduced the time to the peak of the excitatory response in asthmatic subjects, although the values remained longer than in the control subjects. Conclusions - This study reveals impaired reflex excitation of inspiratory motoneurones in asthmatic subjects which could contribute to the reduced ability of these subjects to drive the diaphragm during maximal volitional efforts.

(Thorax 1996;51:490-495)

Keywords: respiratory muscles, reflex, asthma.

It is unclear whether the development of ventilatory failure in acute exacerbations of asthmatic airway narrowing is due to respiratory muscle fatigue or to central failure to increase motoneuronal drive sufficient to maintain alveolar ventilation. Motoneuronal output to a muscle depends not only on the extent of descending drive, but also on the net contribution of reflex facilitation and inhibition at a spinal level.

Asthmatic subjects have an impaired capacity to activate the diaphragm during attempted maximal voluntary inspiratory efforts compared with control subjects ${ }^{1}$ and there is an association between impaired voluntary drive and a measure of depressed mood. ${ }^{2}$ This suggests a reduction in descending drive but the possibility has not been investigated that, in addition, reflex support to the voluntary contraction is reduced. For limb muscles it has been estimated that net facilitatory reflex support from muscle afferents may contribute up to $30 \%$ of the motoneuronal output in both submaximal and maximal voluntary contractions. ${ }^{3-5}$

In the respiratory muscles of healthy subjects reflex responses to inspiratory loading consist of an initial short latency inhibition of electromyographic activity (EMG) and a subsequent longer latency excitation. ${ }^{6-8}$ The responses are probably mediated by muscle spindles and tendon organs in the inspiratory muscles acting on the chest wall because they persist after endotracheal intubation ${ }^{8}$ and are not affected by inhalation of lignocaine. ${ }^{68}$ The long latency excitation is probably mediated by supraspinal pathways. ${ }^{6-8}$ These reflex responses are of particular interest because the equivalent responses in limb muscles (that is, stretch reflexes) consist of two excitatory peaks of EMG with no initial or intervening reflex inhibition. ${ }^{9-11}$

There have been no reports of the short latency reflex responses to loading of inspiratory muscles in asthmatic subjects. If the net reflex facilitation to the respiratory motoneurones was reduced in asthmatic subjects, the output of inspiratory motoneurones in response to descending drive would be reduced, possibly contributing to the inability of some subjects to achieve maximal voluntary activation of their diaphragm. In this study, we have therefore measured the reflex responses of inspiratory muscles to airway occlusion in asthmatic subjects under control conditions and during bronchoconstriction.

\section{Methods}

Experiments were performed on nine healthy asthmatic subjects (five women) and 12 nonasthmatic control subjects (five women) matched for age, height and weight. The mean (SE) age of the asthmatic subjects was 30 (4) years (range 17-51), weight 66 (2) kg (range 57-74) and height 170 (4) cm (range 157-188). Data for the non-asthmatic subjects were taken from a larger sample of subjects from a previous study. ${ }^{8}$ These control subjects did not differ significantly from the asthmatic subjects in age (33 (2) years), weight (68 (3) $\mathrm{kg}$ ), or height $(172(2) \mathrm{cm})$. The asthmatic subjects were recruited by advertisements in newsletters published by the hospital, the associated university, 
A

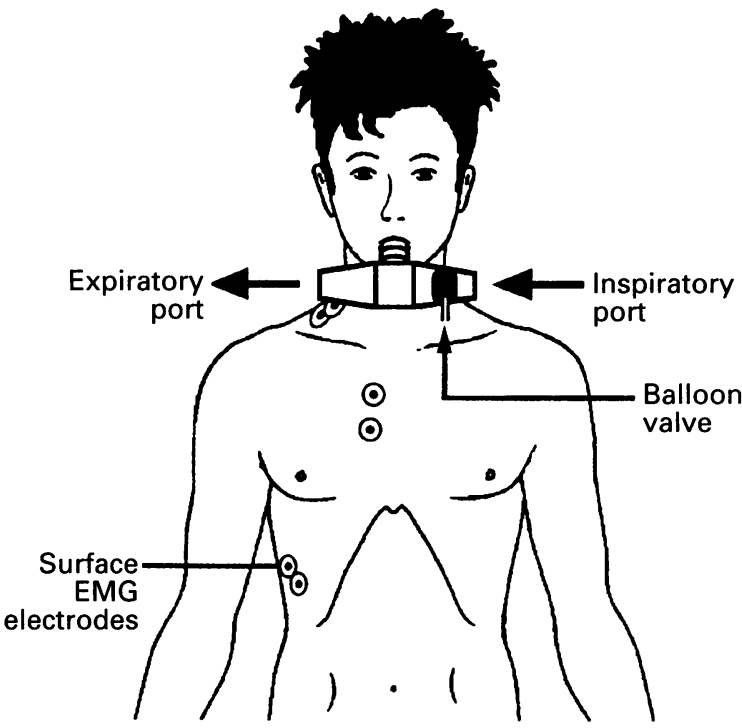

B

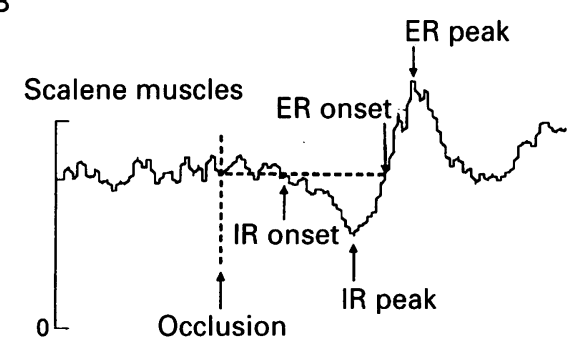

Diaphragm

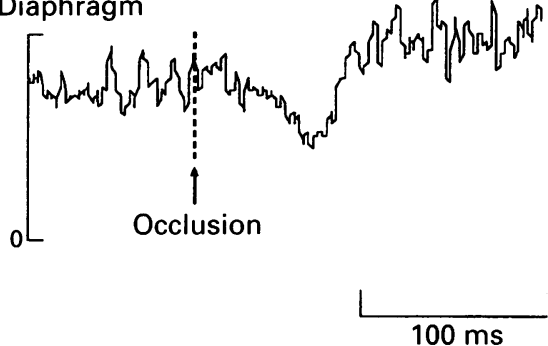

Figure 1 Experimental setup and description of measurements. (A) Placement of surface electrodes and occlusion valve. (B) Mean of 30 rectified trials from recordings from a typical control subject in scalene muscles, showing the points where latencies and amplitudes of responses were measured, and crural diaphragm. Vertical calibration: scalenes $10 \mu V$; diaphragm $6 \mu \mathrm{V}$. Onset of the occlusion at the vertical dashed line. Horizontal dashed line represents mean level of prestimulus EMG activity.

and the Asthma Foundation of New South Wales. A telephone questionnaire was used to screen respondents to confirm the presence of

A

Scalene muscles

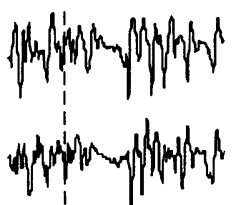

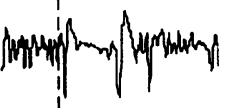

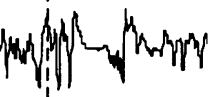

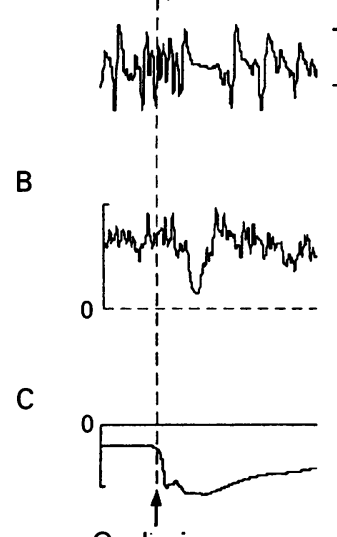

Occliusion
Parasternal intercostal muscles
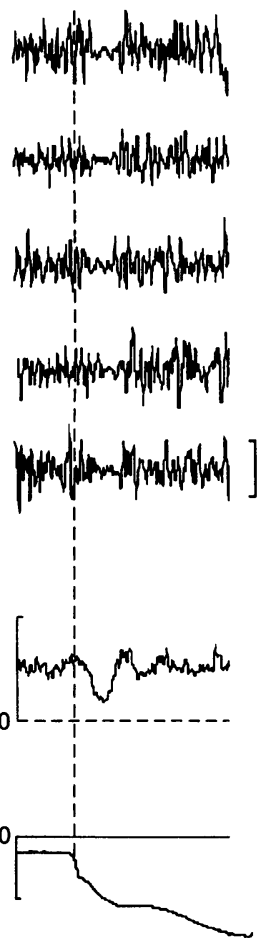

Lateral
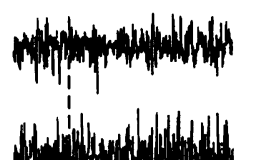

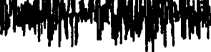



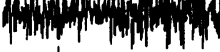
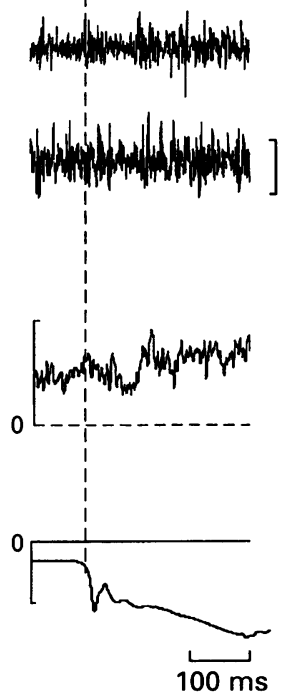
chest wall

Figure 2 Single and mean responses to airway occlusion in three asthmatic subjects. $(A)$ Five single trials of raw EMG from scalene, parasternal intercostal, and lateral chest wall recordings. Subjects were instructed to "breathe through" the occlusion. Vertical calibrations: $500 \mu \mathrm{V}$ (scalene muscles), $18 \mu \mathrm{V}$ (parasternal intercostal muscles), and $3 \mu \mathrm{V}$ (lateral chest wall). (B) Means of each set of five trials in (A) following rectification. Vertical calibration: $200 \mu V$ (scalene muscles), $6 \mu V$ (parasternal intercostal muscles), and $1 \mu \mathrm{V}$ (lateral chest wall). (C) Mean mouth pressure trace for each set of trials. Vertical calibration: $8 \mathrm{~cm} \mathrm{H}_{2} \mathrm{O}$ For all panels onset of occlusion is represented by the vertical dashed line.

current or recent asthmatic symptoms requiring medication (within three months), that a doctor had diagnosed asthma, and to exclude subjects with significant intercurrent illnesses. All the recruited subjects were taking medication for asthma. Seven were using a combination of an inhaled corticosteroid and an inhaled short acting $\beta$ agonist, one was using inhaled salbutamol alone, and one was using an inhaled corticosteroid, salmeterol, and a short acting $\beta$ agonist. Three subjects had been admitted to hospital previously for a severe exacerbation of asthmatic airway narrowing.

The procedures were approved by the appropriate institutional ethics committee and informed consent was obtained.

LUNG FUNCTION

Lung function tests were performed on all subjects while seated in a pressure compensated body plethysmograph. Airflow at the mouth was obtained from a pneumotachometer (Hans Rudolph Model 3800, Missouri, USA). Mouth pressure was measured proximal to the shutter and valve box. The following data were measured: functional residual capacity (FRC), total lung capacity (TLC), slow vital capacity (VC), forced expiratory volume in one second $\left(\mathrm{FEV}_{1}\right)$, forced vital capacity (FVC), and forced expiratory ratio (FER) (table 1). Asthmatic subjects were studied during bronchoconstriction and when airway function was close to optimal. They took no bronchodilator medications for six hours prior to the study (18 hours for salmeterol). Six subjects were studied initially while they were well and subsequently during bronchoconstriction following inhalational challenge (see below). Three of these subjects were also studied following the reversal of bronchoconstriction by inhalation of salbutamol 
Table 1 Lung function data for the control and asthmatic subjects

\begin{tabular}{lllllll}
\hline & $\begin{array}{l}\text { TLC } \\
\text { (\% pred) }\end{array}$ & $\begin{array}{l}\text { FRC } \\
\text { (\% pred) }\end{array}$ & $\begin{array}{l}F V C \\
\text { (\% pred })\end{array}$ & $\begin{array}{l}F E V_{1} \\
(\% \text { pred })\end{array}$ & $\begin{array}{l}\text { BC FEV } \\
\text { (\% pred) }\end{array}$ & $\begin{array}{l}F E R \\
(\%)\end{array}$ \\
\hline $\begin{array}{c}\text { Asthmatic } \\
\text { subjects }\end{array}$ & $104(7)$ & $106(14)$ & $95(7)$ & $79(9)^{*}$ & $52(3)$ & $71(5)$ \\
$\begin{array}{c}\text { Control } \\
\text { subjects }\end{array}$ & $107(6)$ & $103(8)$ & $116(8)$ & $110(6)$ & - & $80(3)$ \\
\hline
\end{tabular}

TLC = total lung capacity; FRC $=$ functional residual capacity; FVC = forced vital capacity; $\mathrm{FEV}_{1}=$ forced expiratory volume in one second (either before $(\mathrm{n}=6)$ or after $(\mathrm{n}=3)$ bronchodilator); $\mathrm{BC} \mathrm{FEV}_{1}=\mathrm{FEV}$, measured during bronchoconstriction); $\mathrm{FER}=$ forced expiratory ratio. ${ }^{*} \mathrm{p}<0.05$ versus controls.

(400 $\mu \mathrm{g}$ via a large spacer (Volumatic)). The remaining three subjects had moderate bronchoconstriction on arrival $\left(\mathrm{FEV}_{1}<70 \%\right.$ predicted) and were studied before and after bronchodilation.

RECORDING OF ELECTROMYOGRAPHIC ACTIVITY (EMG)

Electromyographic activity (EMG) was recorded from the scalenes, parasternal intercostals, and lateral chest wall muscles using surface electrodes (fig 1A). For the scalene muscles one electrode was placed in the posterior triangle at the level of the cricoid cartilage with the other about $4 \mathrm{~cm}$ inferior. For the parasternal intercostal muscles one electrode was placed over the second or third intercostal space $2-3 \mathrm{~cm}$ from the edge of the sternum while the other was placed on an adjacent rib or on the sternum such that the interelectrode distance was $4 \mathrm{~cm}$. Electrodes were also placed over the lateral chest wall $4 \mathrm{~cm}$ apart, one on the anterior axillary line in the seventh intercostal space overlying costal diaphragm and the other on the costal margin $4 \mathrm{~cm}$ inferiorly. The latter electrodes recorded from both the chest wall muscles (abdominal and intercostal) and the underlying costal diaphragm. ${ }^{1213}$ EMG signals were amplified (Digitimer, D150 amplifers, Welwyn, UK) and filtered with a band width of $53 \mathrm{~Hz}-1 \cdot 0 \mathrm{kHz}$.

The EMG recording methods used in the present study have been validated previously. ${ }^{8}$ Similar responses were noted in recordings from both surface and intramuscular hook wire electrodes in scalene and parasternal intercostal muscles, and from chest wall and oesophageal electrodes used to record EMG from the costal and crural diaphragm (fig 1B). In the present study oesophageal and intramuscular electrodes were not routinely used so that tonic reflex inputs were not altered by invasive procedures.

EXPERIMENTAL PROTOCOL

Subjects were seated comfortably in a body plethysmograph and breathed through a low resistance airway and voluntarily maintained a constant inspiratory flow (about $0.5 \mathrm{l} / \mathrm{s}$ using visual feedback) through a low resistance valve (Hans Rudolph Model 3800). Subjects chose their own tidal volume and respiratory frequency but the tidal volume was generally increased compared with eupnoea. An airway occlusion lasting about $250 \mathrm{~ms}$ was delivered without warning during the inspiratory phase of randomly selected breaths (approximately one in three) by a silent balloon valve in the inspiratory line (Hans Rudolph Model 9300). The balloon valve operated at high pressure to reduce inflation time such that inspiratory flow was halted within $10 \mathrm{~ms}$. This brief occlusion during inspiration resulted in a small decrease in mouth pressure of $2-8 \mathrm{~cm} \mathrm{H}_{2} \mathrm{O}$. To avoid contamination of the EMG responses the occlusion was triggered by the QRS complex of the electrocardiogram (ECG) and delayed for each subject so that the ECG trace was flat $100 \mathrm{~ms}$ before and $300 \mathrm{~ms}$ after the onset of the occlusion. Subjects were told to "breathe through" the occlusion with the same constant inspiratory effort. This is equivalent to the "do not intervene" instruction commonly used in studies of reflex responses in limb muscles. ${ }^{914}$

\section{BRONCOCONSTRICTION}

Bronchoconstriction was achieved in six subjects by inhalation of increasing concentrations of histamine phosphate (doubling from $0.25 \mathrm{mg} / \mathrm{ml}$ to $32 \mathrm{mg} / \mathrm{ml}$ ) until the subject's $\mathrm{FEV}_{1}$ decreased to about $50 \%$ of the predicted value. Three subjects whose $\mathrm{FEV}_{1}$ was below $70 \%$ of predicted on arrival were studied before and after bronchodilation using salbutamol. Subjects breathed with the same controlled inspiratory flow whether under bronchoconstricted or "control" conditions $(0.5 \mathrm{l} / \mathrm{s})$.

\section{DATA ANALYSIS}

Each subject performed four sets of 30 trials (two control sets and two sets while bronchoconstricted). EMG, mouth pressure, and lung volume signals were recorded for $100 \mathrm{~ms}$ before and $300 \mathrm{~ms}$ after the onset of the airway occlusion. Signals were monitored on line and were stored on a computer through an interface with a sampling rate of $2 \mathrm{kHz}$ (CED 1401, Cambridge Electronic Design, Cambridge, $\mathrm{UK})$. Repeated measurements of $\mathrm{FEV}_{1}$ were obtained after each set of 30 trials.

Measurements of the background EMG level and the latencies and sizes of the responses to occlusion were made from rectified averages of 30 trials using cursors and conventional definitions of inhibition and excitation. Latencies were measured from the time when inspiratory flow was reduced to zero by the occlusion (termed onset of the occlusion). At this time, airway pressure had decreased by about $20 \%$ of the total decrease produced by the occlusion. Latencies were measured at the onset and peak of the inhibition (IRonset and IRpeak, respectively) and the nominal onset and peak of the subsequent excitation (ERonset and ERpeak, respectively). ERonset was measured at the point when the rectified EMG reached the same level as the preocclusion activity (fig 1B). The size of the EMG responses to airway occlusion was expressed as the percentage change from the mean preocclusion level of EMG. 
Table 2 Mean (SE) responses to airway occlusion in asthmatic and control subjects under control conditions

\begin{tabular}{|c|c|c|c|c|c|c|}
\hline & IRonset (ms) & IRpeak (ms) & IRpeak (\%) & ERonset (ms) & ERpeak (ms) & ERpeak (\%) \\
\hline \multicolumn{7}{|l|}{ Asthmatic subjects } \\
\hline Scalene muscles & $35 \cdot 7(1 \cdot 8)$ & $71.9(1.8)^{*}$ & $-39 \cdot 1(2 \cdot 5)$ & $91.9(3.4)^{*}$ & $114 \cdot 7(3 \cdot 9)^{*}$ & $+32 \cdot 4(4 \cdot 3)^{*}$ \\
\hline Parasternal intercostal muscles & $39 \cdot 4(5 \cdot 3)$ & $75 \cdot 3(2 \cdot 3)^{*}$ & $-26.0(2 \cdot 9)$ & $106 \cdot 6(8 \cdot 2)^{*}$ & $125 \cdot 2(9 \cdot 4)^{*}$ & $+30 \cdot 1(3 \cdot 7)^{*}$ \\
\hline Lateral chest wall & $38.9(3.5)$ & $71 \cdot 3(2 \cdot 5)^{*}$ & $-25 \cdot 1(3 \cdot 2)$ & $109 \cdot 3(9 \cdot 4)^{*}$ & $123.9(9.9)^{*}$ & $+28.9(5.2)^{*}$ \\
\hline \multicolumn{7}{|l|}{ Control subjects } \\
\hline Scalene muscles & $33 \cdot 5(2 \cdot 4)$ & $58 \cdot 0(3 \cdot 5)$ & $-38 \cdot 2(5 \cdot 2)$ & $76 \cdot 27(4 \cdot 5)$ & $96 \cdot 5(6 \cdot 3)$ & $+43 \cdot 3(6 \cdot 1)$ \\
\hline Parasternal intercostal muscles & $37.5(3 \cdot 8)$ & $60 \cdot 6(3 \cdot 4)$ & $-35 \cdot 4(4 \cdot 0)$ & $82.6(5.0)$ & $103.5(5 \cdot 2)$ & $+41 \cdot 4(5 \cdot 3)$ \\
\hline Lateral chest wall & $40 \cdot 0(3 \cdot 5)$ & $63 \cdot 7(3 \cdot 6)$ & $-26.0(3.5)$ & $79 \cdot 7(4 \cdot 4)$ & $100 \cdot 7(5 \cdot 1)$ & $+45.9(6.6)$ \\
\hline
\end{tabular}

The amplitude of the peak is expressed relative to the mean background level of EMG prior to the occlusion.

$\mathrm{IR}=$ inhibitory response; $\mathrm{ER}=$ excitatory response.

${ }^{*} \mathrm{p}<0.05$ versus controls.

\section{STATISTICS}

An analysis of variance was performed on all data to determine the effects of bronchoconstriction within the asthmatic group and to determine whether the latencies and relative amplitudes of the EMG responses differed between asthmatic and non-asthmatic subjects. Student's $t$ tests were used post hoc to determine the significance of differences in the latency and size of the responses in specific muscles. Statistical significance was set at the $5 \%$ level. Values are given as mean (SE). For the text, data have been pooled across muscles to show the general trend of results. Data for individual muscles are given in tables 2 and 3.

\section{Results}

Short and long latency EMG responses to airway occlusion were observed consistently in all asthmatic subjects in recordings from surface electrodes overlying the scalenes, parasternal intercostal, and "lateral chest wall" muscles. At each site the responses consisted of a marked short latency inhibition (inhibitory response, IR) and a subsequent excitatory response (ER). They were apparent in single trials and in averages of rectified EMG (fig 2). When data from all recording sites were pooled, the onset of IR (IRonset) was at $38 \mathrm{~ms}$ with a peak at $73 \mathrm{~ms}$, while the onset and peak of ER occurred at $103 \mathrm{~ms}$ and $121 \mathrm{~ms}$, respectively. This pattern of inhibition of EMG activity followed by

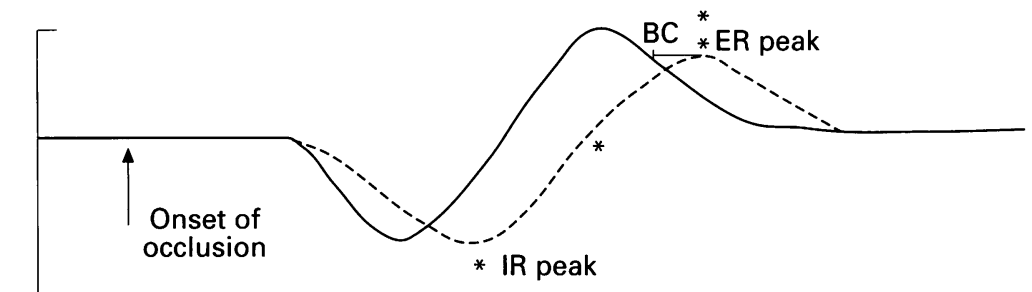

\section{$50 \mathrm{~ms}$}

Figure 3 Diagrammatic representation of responses to airway occlusion in asthmatic $(---)$ and control subjects $(-\longrightarrow)$ showing mean data for the latencies and sizes of responses to airway occlusion. Note that the latencies to IRpeak, ERonset, and ERpeak are significantly (*) longer for the asthmatic subjects and that the size of ERpeak is significantly reduced in the asthmatic subjects. Onset of occlusion indicated by arrow. The decrease in average latency of ERpeak when the subjects were bronchoconstricted is indicated by the horizontal bar labelled ' $B C$ '. All values for the asthmatic and control
intere subjects are calculated from the mean results for the three muscles in the absence of bronchoconstriction. excitation is qualitatively similar to that for nonasthmatic subjects ${ }^{78}$ but there were significant differences in the size and timing of the responses.

Table 2 compares data for latencies and relative amplitudes of the EMG responses for the three inspiratory recording sites in asthmatic and non-asthmatic subjects under control conditions. An analysis of variance showed that the average latency to the onset of the inhibitory EMG response across all muscles (IRonset, about $38 \mathrm{~ms}$ ) was similar for the two groups of subjects. The size of the IRpeak (32\% reduction in EMG) was also similar. However, the average latency for the IRpeak in asthmatic subjects ( $73 \mathrm{~ms}$ ) was $12 \mathrm{~ms}$ longer than in nonasthmatic subjects $(61 \mathrm{~ms} ; \mathrm{p}<0.01)$. The average latencies to ERonset and ERpeak in asthmatic subjects $(103 \mathrm{~ms}$ and $121 \mathrm{~ms}$, respectively) were $23 \mathrm{~ms}$ and $21 \mathrm{~ms}$ longer $(p<0.01)$ than in non-asthmatic subjects. Thus, the estimated duration of the inhibitory response (ERonset minus IRonset) was prolonged by about $50 \%$ in the asthmatic group (non-asthmatic $42.7 \mathrm{~ms}$, asthmatic $64.6 \mathrm{~ms}$ ). In addition, the average size of ERpeak was about $30 \%$ smaller in asthmatic subjects than in control subjects $(+30 \%$ versus $+44 \%$, $\mathrm{p}<0.01)$. To illustrate the differences between the groups, fig 3 depicts the average response to occlusion of inspiratory muscles of asthmatic subjects superimposed on the average response from control subjects. Although it is not possible here to differentiate between prolongation of the inhibition and/or a reduction of the subsequent excitation, the net reflex response of the inspiratory motoneurones to loading is decreased for the asthmatic subjects.

\section{BRONCHOCONSTRICTION}

During "bronchoconstriction" the mean $\mathrm{FEV}_{1}$ was 52 (3)\% predicted and about $65 \%$ of the initial control value or that obtained following bronchodilation (table 1). The absolute level of EMG required to achieve the target inspiratory. flow was increased in all muscles during bronchoconstriction to 1.8 times the control level during bronchoconstriction in scalene muscles $(\mathrm{p}<0.01), 2.5$ times in parasternal intercostal muscles $(\mathrm{p}<0.05)$, and 1.5 times in lateral chest wall recordings $(\mathrm{p}<0 \cdot 48) .{ }^{1516}$

Figure 4 shows responses from a typical asthmatic subject in the three muscles recorded under control conditions and during bronchoconstriction. Within the asthmatic group latencies to IRonset, IRpeak, and ERonset were 
Scalene muscles

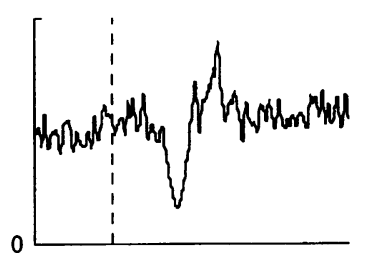

Parasternal

intercostal muscles

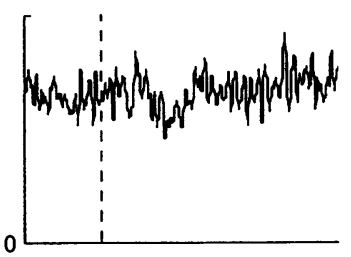

Lateral

chest wall

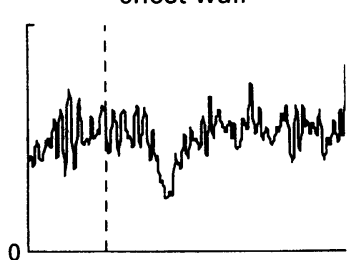

B
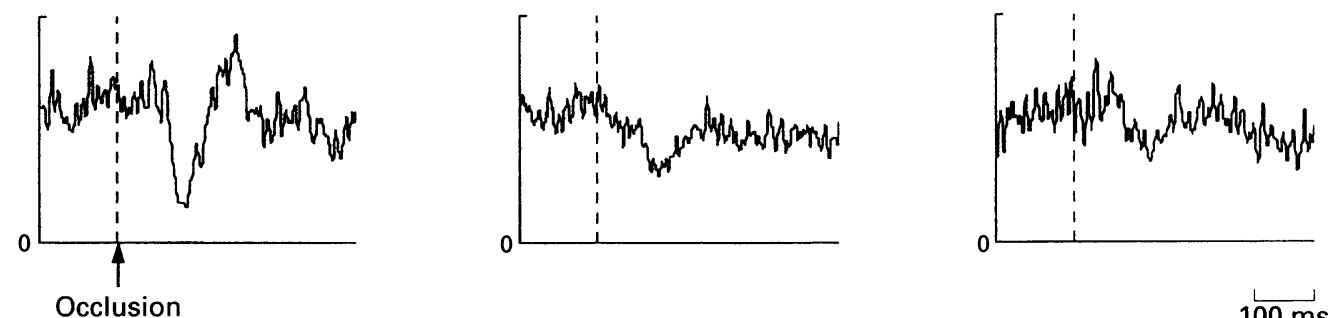

$100 \mathrm{~ms}$

Figure 4 Responses to airway occlusion during bronchoconstriction in an asthmatic subject for scalene muscles, parasternal intercostal muscles, and lateral chest wall EMG recordings. The mean of 30 rectified trials is shown in each panel $(A)$ while under control conditions (108\% predicted $F E V$ ) and $(B)$ while bronchoconstricted with histamine (48\% predicted $F E V$ ). Onset of the occlusion at the vertical dashed line. Vertical calibrations for control and bronchoconstricted conditions: scalene muscles $30 \mu \mathrm{V}$; parasternal intercostal muscles $6 \mu \mathrm{V}$; lateral chest wall $7 \cdot 5 \mu \mathrm{V}$.

Table 3 Mean (SE) responses to airway occlusion in asthmatic subjects during bronchoconstriction

\begin{tabular}{|c|c|c|c|c|c|c|}
\hline & IRonset (ms) & IRpeak (ms) & IRpeak (\%) & ERonset (ms) & ERpeak (ms) & ERpeak (\%) \\
\hline $\begin{array}{l}\text { Scalene muscles } \\
\text { Parasternal intercostal muscles } \\
\text { Lateral chest wall }\end{array}$ & $\begin{array}{l}31 \cdot 3(1 \cdot 9) \\
36 \cdot 3(3 \cdot 0) \\
43 \cdot 4(3 \cdot 5)\end{array}$ & $\begin{array}{l}67 \cdot 1(1 \cdot 9) \\
67 \cdot 8(i \cdot 9) \\
77 \cdot 7(2 \cdot 4)\end{array}$ & $\begin{array}{l}-45 \cdot 5(3.6) \\
-32.5(3 \cdot 8) \\
-21.5(3.2)\end{array}$ & $\begin{array}{l}90 \cdot 8(3 \cdot 6) \\
96 \cdot 4(6 \cdot 3) \\
98 \cdot 7(6 \cdot 3)\end{array}$ & $\begin{array}{l}106 \cdot 9(3.4)^{*} \\
102 \cdot 2(3.5)^{*} \\
112 \cdot 7(7 \cdot 8)^{*}\end{array}$ & $\begin{array}{l}+43 \cdot 1(5 \cdot 7) \\
+35 \cdot 5(3 \cdot 8) \\
+25 \cdot 9(5 \cdot 6)\end{array}$ \\
\hline
\end{tabular}

The amplitude of the peak is expressed relative to the mean background level of EMG prior to the occlusion.

${ }^{*} \mathrm{p}<0.05$ versus corresponding bronchodilated values in asthmatic subjects (table 2 ).

unaffected by bronchoconstriction, although the time to ERpeak was significantly shorter $(\mathrm{p}<0.05)$. Table 3 shows values for each muscle. The estimated duration of inhibition was still significantly longer than in control subjects (by $31 \%$ ). For the two muscles which showed a detectable increase in activity during bronchoconstriction (scalene and parasternal muscles) the amplitudes of IRpeak and ERpeak were slightly larger during bronchoconstriction (compare tables 2 and 3 ).

\section{Discussion}

These results document a reduction in the net excitation reaching inspiratory motoneurones in asthmatic subjects during loaded inspiration compared with non-asthmatic subjects. When clinically well, the duration of the initial inhibition produced by transient airway occlusion in asthmatic subjects increased by about $50 \%$ and the amplitude of the subsequent facilitation was $30 \%$ smaller than in non-asthmatic subjects. When bronchoconstricted, the duration of the initial inhibition in asthmatic subjects was still increased by about $30 \%$ compared with non-asthmatic subjects, despite increased voluntary drive to breathe. This decrease in motoneuronal facilitation could be deleterious to ventilation although it might act to limit the hyperinflation which accompanies severe airway narrowing. In addition, decreased reflex facilitation would make it more difficult for supraspinal pathways to achieve complete activation of the inspiratory motoneurones since facilitatory reflex support from muscle afferents contributes a substantial portion of the neural drive to a voluntary contraction in limb muscles ${ }^{34}$ and intercostal muscles. ${ }^{6}$

The increased duration of the inhibitory response in asthmatic subjects may reflect some tonic inhibition acting on inspiratory motoneurones which effectively delays their recovery after a phasic inhibition. The amplitude of the decrease in EMG did not differ from that in non-asthmatic subjects. However, postural activity in the inspiratory muscles may limit the extent to which the EMG level can drop during phasic inhibition. Thus, the inhibitory responses could be effectively maximal in control subjects so that additional inhibition may be manifest only as prolongation of inhibition. Alternatively, the long latency excitatory response may be delayed and/or inhibited along its supraspinal pathway.

The altered reflex responses observed in asthmatic subjects are unlikely to represent an artifact related to alterations in lung volume or neural drive. There was no difference between the groups in FRC measured under control conditions when the asthmatic subjects were not bronchoconstricted and the same inspiratory flow was used. The chronic airways inflammation of asthma changes the neural control of the airways ${ }^{17} 18$ and afferents from airways have indirect connections with res- 
piratory motoneurones. Bronchoconstriction may be due to increased cholinergic neurotransmission, abnormal $\beta$ adrenoceptor function as a result of chronic inflammation or adrenergic therapy, and impairment of nonadrenergic and non-cholinergic bronchodilation. Chronic inflammation of the airways will increase release of tachykinins (including substance $P$ and neurokinin $A$ ) from proliferated unmyelinated nerve terminals. ${ }^{17}$ These changes may alter the tonic input to spinal or supraspinal respiratory neurones and thereby modify reflex responses. Our results suggest that the altered reflex responses of asthmatic subjects are not simply related to a reduction in airway calibre because additional narrowing does not further prolong the inhibition.

Alternatively, repetitive loading of the inspiratory muscles as a result of recurrent or chronic airway narrowing may lead to adaptation, not only of muscles ${ }^{19}{ }^{20}$ but also the reflex responses. Strength and resistance training increase voluntary strength and alter the twitch properties and reflex behaviour of limb muscles. ${ }^{21-24}$ Although the results of the latter studies are not entirely consistent, one reported a decrease in the size of the tendon jerk following strength or resistance training. ${ }^{22}$

The results of this study do not reveal the mechanisms for the apparent prolongation of the reflex "inhibition" in the asthmatic subjects. Furthermore, it is difficult to estimate the pathophysiological significance of these changes in reflex facilitation in terms of motoneuronal excitability and motor drive to the inspiratory muscles. However, these results may help to explain the observation that some asthmatic subjects have an impairment of voluntary drive to the diaphragm. ${ }^{1}$ Indeed, they suggest that the reflex pathways and the descending voluntary drive to the inspiratory motoneurones share a common site at which the "inhibition" is manifest. Overall, achievement of a given output from inspiratory motoneurones may require a greater descending drive in asthmatic subjects. This may have the potential to increase the risk of ventilatory failure in severe exacerbations of asthmatic airway narrowing.

This work was supported by the National Health and Medical Research Council of Australia and the Asthma Foundation of New South Wales. The authors would like to thank Ms G Allen for her comments and assistance.
1 Allen GM, McKenzie DK, Gandevia SC, Bass S. Reduced voluntary drive to breathe in asthmatic subjects. Respir Physiol 1993;93:29-40.

2 Allen GM, Hickie I, Gandevia SC, McKenzie DK. Impaired voluntary drive to breathe: a possible link between asthma and depression and unexplained ventilatory failure in asthand depression and unexplained ventila

3 Gandevia SC, Macefield G, Burke D, McKenzie DK. Voluntary activation of human motor axons in the absence of muscle afferent feedback: the control of the deafferented hand. Brain 1990;113:1563-81.

4 Gandevia SC, Macefield VG, Bigland-Ritchie B, Gorman $\mathrm{RB}$, Burke D. Motoneuronal output and gradation of effort in attempts to contract acutely paralysed leg muscles in man. $\mathcal{f}$ Physiol (Lond) 1993;471:411-27.

5 Bongiovanni LG, Hagbarth K-E. Tonic vibration reflexes elicited during fatigue from maximal voluntary contractions in man. $f$ Physiol (Lond) 1990;423:1-14

6 Newson Davis J, Sears TA. The proprioceptive reflex control of the intercostal muscles during their voluntary activation. f Physiol (Lond) 1970;209:711-38.

7 Plassman BL, Lansing RW, Foti K. Inspiratory muscle responses to airway occlusion during learned breathing movements. F Neurophysiol 1987;57:274-88.

8 Butler JE, McKenzie DK, Crawford MR, Gandevia SC. Role of airway receptors in the reflex responses of human inspiratory muscles to airway occlusion. $\mathcal{F}$ Physiol (Lond) 1995;487:273-81.

9 Hammond $\mathrm{PH}$. The influence of prior instruction to the subject on an apparently involuntary neuromuscular resubject on an apparently involuntary neuro
sponse. $¥$ Physiol (Lond) 1956;132:17-18P.

10 Marsden CD, Merton PA, Morton HB. Stretch reflex and servo action in a variety of human muscles. 7 Physiol servo action in a variety
(Lond) $1976 ; 259: 531-60$.

11 Capaday C, Forget R, Fraser R, Lamarre Y. Evidence for a contribution of the motor cortex to the long-latency stretch reflex of the human thumb. $\mathcal{F}$ Physiol (Lond) 1991;440: 243-55.

12 Lansing RW, Savelle J. Chest surface recording of diaphragm potentials in man. Electroencephalogr Clin Neurophysiol 1989;72:59-68.

13 Gandevia SC, McKenzie DK. Human diaphragmatic EMG: changes with lung volume and posture during supra-
maximal phrenic stimulation. $f$ Appl Physiol 1986;60: maximal

14 Doemges F, Rack PMH. Task-dependent changes in the response of human wrist joints to mechanical disturbance. f Physiol (Lond) 1992;447:575-85.

15 Muller N, Bryan AC, Zamel N. Tonic inspiratory muscle activity as a cause of hyperinflation in asthma. $\mathcal{f} A p p$ Physiol 1981;50:279-82.

16 Martin JG, Shore SA, Engel LA. Mechanical load and inspiratory muscle action during induced asthma. Am Rev Respir Dis 1983;128:455-60.

17 Barnes PJ. Neural mechanisms in asthma. Br Med Bull 1991;48:149-68.

18 Ollerenshaw SL, Woolcock AJ. Characteristics of the inflammation in biopsies from large airways of subjects with asthma and subjects with chronic airflow limitation. $\mathrm{Am}$ asthma and subjects with chronic
Rev Respir Dis 1992;145:922-7.

19 McKenzie DK, Gandevia SC. Strength and endurance of inspiratory, expiratory, and limb muscles in asthma. $\mathrm{Am}$ Rev Respir Dis 1986;134:999-1004.

20 Newell SZ, McKenzie DK, Gandevia SC. Inspiratory and skeletal muscle strength and endurance and diaphragmatic activation in patients with chronic airflow limitation. Thorax 1989;44:903-12.

21 Milner-Brown HS, Stein RB, Lee RG. Synchronization of human motor units: possible roles of exercise and supraspinal reflexes. Electrencephalogr Clin Neurphysiol supraspinal reflex

22 Sale DG, McComas AJ, MacDougall JD, Upton ARM Neuromuscular adaptation in human thenar muscles following strength training and immobilization. 7 Appl Physiol 1982;53:419-24.

23 Sale DG, Upton ARM, McComas AJ, MacDougall JD. Neuromuscular function in weight trainers. Exp Neurol 1983;82:521-31.

24 Häkkinen K, Komi PV. Training-induced changes in neuromuscular performance under voluntary and reflex conditions. Eur F Appl Physiol 1986;55:147-55. 